\title{
Deployable structures classification: A review
}

\author{
Giulia E Fenci and Neil GR Currie
}

\begin{abstract}
Deployable structures have the capacity to transform and predictably adopt multiple predetermined configurations, moving through known paths, while deploying in a controlled and safe way. These characteristics introduce benefits when considering issues such as ease of transportation, erection and the overall sustainability of the structure by means of high material efficiency, modularisation and maximum use of natural energy resources. The aim of this article is to provide a critical review of existing attempts at classifying deployable structures identifying connections between different families through their mechanical and structural behaviours. The classifications selected consider theoretical and applied deployable structures, not focusing on a single application of deployable structures but including those ranging from spatial applications, to temporary and disaster relief structure, through to medical applications, providing coherence where terminology varies between applications. In order to gain a consistent understanding, tree diagrams were created for the review/classification to allow drawing commonalities and establishing differences between authors. A chronological approach was adopted, using key review work as focal points for the timeline, complemented by smaller more specific pieces of work. This enabled the identification of common features and divergences between the different authors, bringing to the conclusion that a clear, comprehensive, consistent and unified classification of deployable structures is currently missing within the field.
\end{abstract}

\section{Keywords}

classification, deployable structures, kinetic, transformable

\section{Introduction}

The interest in deployable structures and their multiple applications, from space structures ${ }^{1}$ to temporary architecture $^{2}$ and medical devices, ${ }^{3}$ has significantly increased since the second half of the 20th century, as has the research in this emerging field. In the discipline of architecture, the future of design is based on the creation of dynamic and flexible spaces ${ }^{4}$ by virtue of convertible, temporary and lightweight structures for a sustainable form of engineering made necessary by the decrease in natural resources, global climate variations and rapidly increasing population. ${ }^{5}$

Among the review papers in the field of deployable structures, some of the literature proposes classifications of such structures, while some authors do not overtly carry out a classification, preferring to list types of deployable structures along with showing relevant application-based examples. Furthermore, some of the more substantial reviews were published some years ago, and new technologies and types of deployable structures have since been developed, for example, tensairities ${ }^{6}$ invented at the beginning of the 21 st century.

There is, thus, the need for a comprehensive review to summarise the current status of deployable structures in order to confer some clarity and to recognise patterns and trends that could aid in the creation of a new state of the art classification. As new technological developments in the

University of Salford, Manchester, UK

\section{Corresponding author:}

Giulia E Fenci, Civil Engineering, University of Salford, Manchester, Newton Building, 43 Crescent, Salford M5 4WT, UK.

Email: g.e.fenci@edu.salford.ac.uk 
field of deployable structures occur, the need to update the classification of deployable structures will persist.

\section{Literature review}

Transformable structures possess the ability to change morphology and readjust in response to varying conditions and needs that can include changing environment and climatic conditions, different functional requirements and emergency situations. Depending on how the transformation is carried out, transformable structures can be deployable or demountable. De Temmerman et al. ${ }^{7}$ recognise these two groups and distinguish them as follows:

- Structures with kinematic mechanisms that allow the structure to deploy from a small, tight configuration to an open, expanded one able to fulfil its architectural purpose;

- Structures designed as kit-of-parts systems made of basic components that can be reconfigured, replaced and reused.

Some of the reviews that will be discussed include both deployable and demountable structures; however, for the purpose of this article, the focus will be on deployable structures.

The word deployable means to spread out, arrange or utilise for a specific purpose. Etymologically, it derives from the Latin word displicare that means to unfold. ${ }^{8}$ Pellegrino ${ }^{9}$ defines deployable structures as being convertible, having the capacity of undergoing large configuration changes in an autonomous manner and refers to the reverse process as retraction. Deployment describes the transformation these structures carry out from a small, tight and compact configuration to an unfolded and open one reaching a state in which the structure is stable and able to carry loads, see Figure 1. There are some deployable structures, however, that maintain static equilibrium during every stage of deployment, ${ }^{10,11}$ offering even greater range of adaptability. The shape, properties and behaviour of deployable structures can vary to suit external conditions and specific use requirements. ${ }^{12}$

In addition to morphing from small to open, Akgün, ${ }^{13}$ whose research focuses mainly on roof coverings, argues that deployable structures should also include those structures that go through a shape transformation without varying the size of the covered area. Such a principle is suitable for permanent transformable building coverings where the users might want to adapt the shape of the structure according to the way the space is going to be employed. However, Akgün makes a valid point, and such structures are accounted for in this review.

Structurally, numerous loading conditions need to be considered, such as service loads, in the deployed configuration and the dynamics of the deployment. The process is more complex when compared to simple static analysis of

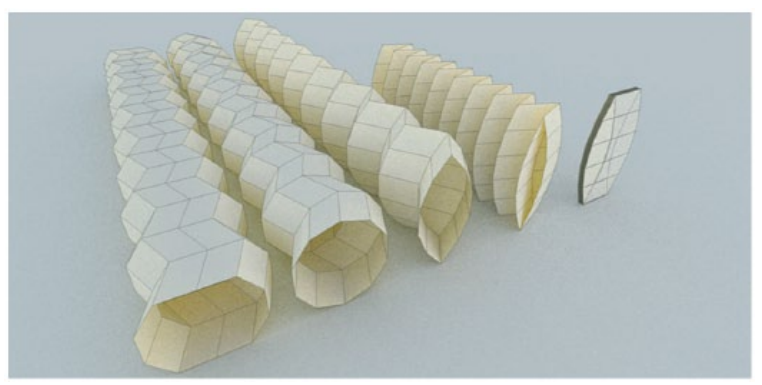

Figure I. Cylindrical deployable structure by Tachi. ${ }^{14}$

ordinary structures, and iterations are necessary to achieve a compromise between design flexibility for deployment and optimum stiffness in the deployed configuration. Additionally, geometric strains may develop during deployment, causing the generation of second-order strains and a non-linear behaviour of the members. ${ }^{15,16}$

The first academics to talk about deployable architecture were Zuk and Clark ${ }^{17}$ proving that research in the field of kinetic structures is fairly recent. In their book, Kinetic Architecture, they wrote about a form of architecture that complied with time-changing effects, quoting literature from the 1960s such as Rowan: ${ }^{18}$

Surely our present task is to unfreeze architecture - to make it fluid, vibrating, changeable backdrop for the varied and constantly changing modes of life. An expanding, contracting, pulsating, changing architecture would reflect life as it is today and therefore be a part of it.

Since then, the concept of an architecture that is capable of modifying its morphology to suit the environment and its users' needs started becoming popular, and various classifications were developed. However, applications for deployable structures do not exclusively relate to architecture but can also be found in other branches of engineering.

\section{Methodology}

The approach was chronological, reviewing the most significant and substantial deployable structures literature over the past 30 years. Figure 2 shows a timeline of the key literature relating the authors to the period during which their work was published. By analysing the literature, two distinct approaches were noticed in the investigation of deployable structures. Some authors went into great depth and proposed a classification: a way for future researchers to make order into the world of deployable structures. Others adopted more of a report style listing the types of deployable structures, but not necessarily trying to class them into specific groups and families. To visualise these different approaches, above the timeline are those who provide an actual classification of deployable structures, and below are those who limited themselves to synthesise or list the different types. 


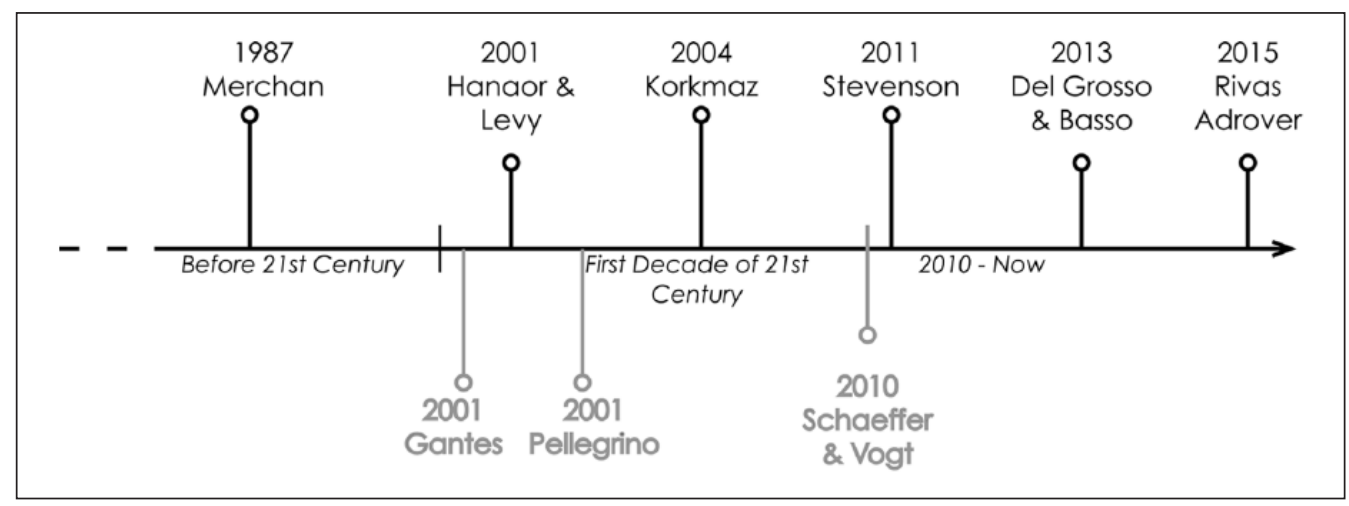

Figure 2. Timeline of deployable structures reviews and classifications.

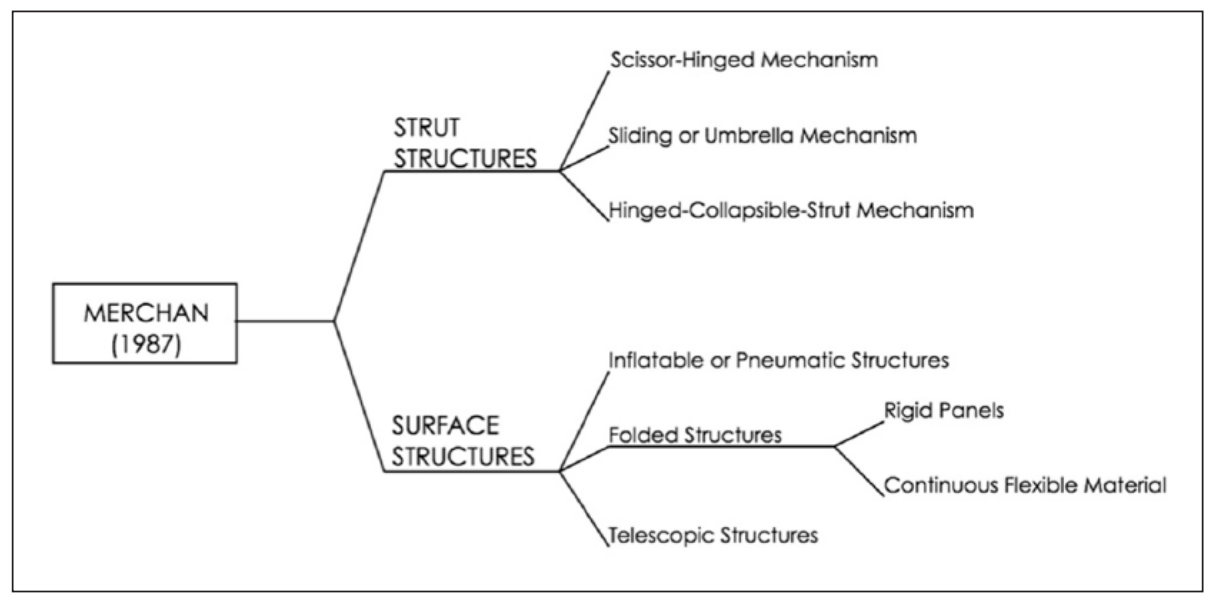

Figure 3. Classification by Merchan. ${ }^{20}$

A tree diagram was created for most of the reviews taken into account in order to offer a visual understanding of the classes and subclasses each author discusses and to identify potential families and connections. The trees were ordered to group common motions/behaviours to assist with future classifications. A similar approach of creating tree diagrams for authors' classifications was previously undertaken by Susam. ${ }^{19}$ However, Susam's work is limited to the reference texts published in the first decade of the 21 st century and primarily focuses on architectural applications, neglecting those deployment mechanisms used in space or medical scenarios.

Due to chronology being an important factor, relating the authors to the advances in deployable structures occurring at their time, the next chapters reflect the three time periods highlighted in Figure 2: before 21st century, first decade of 21 st century and 2010 until current day.

The authors shown in the timeline are not the only ones to write about deployable structures during the time period considered but were selected as representing the most consistent and unifying pieces of work with regard to classification. Other authors allude to classifications of deployable structures in the introduction to their research or carry out a classification of a specific type of deployable structures and are reviewed in a separate chapter.

\section{Before the 2 I st century}

The interest in deployable structures, in particular in the field of architecture, started during the second half of the 20 th century. This is when one of the first attempts at classifying such structures appeared.

\section{Merchan}

One of the first classifications of deployable structures is presented in the master thesis of Carlos H. H. Merchan ${ }^{20}$ in 1987 for the Massachusetts Institute of Technology (MIT). The thesis is not a peer-reviewed article; however, due to there being few examples of deployable structures classifications, it is worth considering. In addition to providing a definition and summary of their applications, the author proposes a general classification stating himself that only the most important structure types are presented, as shown in Figure 3. 
The distinction between strut and surface structures is based on the fact that strut structures resist the load by the elements being in tension, compression or bending, while surface structures are made of continuous surfaces, some of which carry only tension forces. ${ }^{21}$ Scissor-hinged mechanisms $^{22}$ are typically referred to as pantographs ${ }^{23}$ in other classifications. Sliding or umbrella ${ }^{24}$ mechanisms have been neglected by later authors, although they have specific characteristics that are not easily contained within any other category; hence, they should be regarded as belonging to their own class. Hinged-collapsible-strut mechanisms ${ }^{25}$ differ from pantographs in that the struts are only connected to one another by joints located at the ends of the structural elements. Once the structure is fully deployed, the joints are locked in position through brakes or additional restraints, reducing its degrees of freedom to zero, ${ }^{26}$ and the structure behaves as a single element.

With regard to inflatable or pneumatic structures, no distinction is made to the structures being air inflated ${ }^{27}$ or air supported; 28 however, the fact that the liquid must not necessarily be air is mentioned by naming 'pressure differences of gases, liquids, foam, or material in bulk' ${ }^{20}$ Folded structures are divided into those made of rigid panels ${ }^{29}$ connected along their edges and those consisting of continuous flexible material. ${ }^{30}$ Here, the distinction between rigid links and deformable connections (not specified by the author) is evident as forms of folding can occur for both kinematic types. However, when looking at folding specific to membranes, considerations should be made with regard to the membrane being connected to cables or struts and whether the membrane interacts with the other elements or is just supported by them. Finally, Merchan mentions telescopic structures explaining how they are made of tubular elements that slide one inside the other. The sections can either be round or rectangular, as in the example he proposes of a mobile home by Vredevoogd $\mathrm{d}^{31}$ based on rectangular telescopic segments. Nonetheless, Merchan neglects to clarify how such structures do not include only closed segments; examples are firemen ladders and some yacht gangways. Based on the variety of forms in which telescopic structures can be designed, it would be more accurate to include them as being both strut and surface structures.

Although Merchan does consider a variety of deployable structures families, he neglects to consider significant types of deployable structures that had already been developed by the time the thesis was written. These include tensegrities, ${ }^{32,33}$ air-supported structures ${ }^{34,35}$ and sliding structures used for retractable roofs since 1930 s. $^{36}$ Sliding is mentioned with regard to the umbrella mechanism but is never referred to in the context of it being a deployment mechanism on its own.

Ultimately, the main aim of Merchan's thesis is not to provide a classification of deployable structures, but rather to describe some of their geometries, details and mechanism as well as their applications.

\section{First decade of $\mathbf{2}$ I st century}

After Merchan, more than a decade passes before a new synthesis of the subject is undertaken. This occurs in 2001, a year during which three of the main reference texts for the summary and classification of deployable structures were published: Deployable Structures: Analysis and Design by Gantes, ${ }^{37}$ Deployable Structures by Pellegrino 9 and 'Evaluation of deployable structures for space enclosures' by Hanaor and Levy. ${ }^{38}$

\section{Gantes}

Prof. Gantes ${ }^{39}$ obtained his $\mathrm{PhD}$ at the MIT with the thesis A design methodology for deployable structures and is now a professor in the School of Civil Engineering, National Technical University of Athens. His book Deployable Structures: Analysis and Design ${ }^{37}$ is one of the first publications that critically appraises deployable structures. Application governs his first distinction, identifying earth-based and spatial structures, where the self-weight of the structure ceases to be of concern during deployment (see Figure 4). Gantes places great emphasis on identifying different application due to the various assumptions that have to be made for the design, such as the loading type, the factors of safety, the reliability and the degree of automation. However, it can equally be argued that many of these structures can be used in various applications, and although scale, weight and automation mechanisms may vary, the kinematics and morphology are not different enough to justify such a clean-cut distinction between the earth- and space-based applications.

Earth-based structures are classified based on their morphology as follows: pantographs, ${ }^{40}$ two-dimensional (2D) panels, ${ }^{41}$ cable and membrane structures,${ }^{42}$ pneumatic structures, $^{43}$ tensegrities ${ }^{33}$ and retractable roofs. ${ }^{44,45}$ However, Gantes' approach is not consistent throughout as the last category, retractable roofs, is an application of deployable structures, rather than a particular structural shape or form. After this first level of classification, only pneumatic structures and retractable roofs are further divided into air-inflated ${ }^{35}$ and air-supported ${ }^{46}$ (former) and linearly moving systems, radially rotating systems and hybrid (latter).

With regard to pantographs, Gantes references the pioneers such as Piñero ${ }^{40}$ and Zeigler ${ }^{47}$ but does not provide a further classification of these particular deployable structures. Instead, Gantes highlights the contribution of Escrig et al. ${ }^{48,49}$ in their attempt to classify pantographs and twoway deployable spherical grids. ${ }^{50}$ This proves how their work was still influential at the time the book was written, so much that Gantes did not feel the necessity to suggest alterations.

When referring to 2D panels, a particular folding pattern is brought as an example. This is the inextensional wrapping of flat membranes. ${ }^{51}$ Gantes is correct in including the 


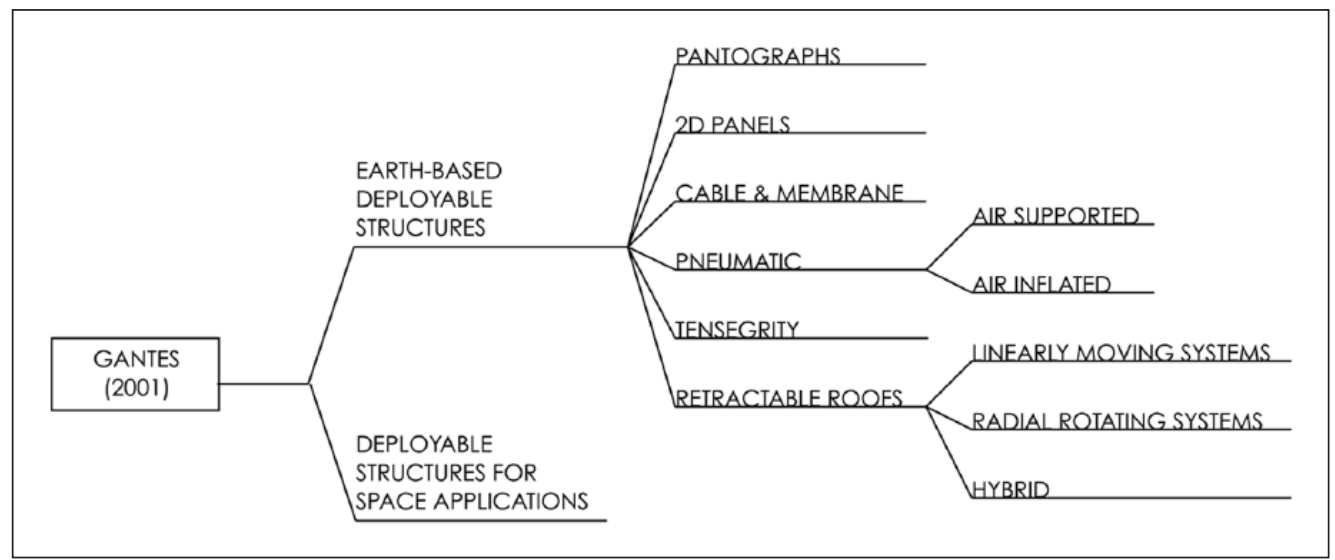

Figure 4. First-level classification by Gantes. ${ }^{39}$

folding pattern within the 2D panel section as it is based on a continuous surface, which achieves its shape by means of creases, but a clarification is necessary when considering the structure's kinematics. The inextensional wrapping belongs to the deformable deployables, ${ }^{52}$ more precisely to deformable origami, unlike all the other examples brought by Gantes that are rigid links. In fact, warping occurs to allow the material to gather around the central hub, contradicting the definition of rigid folding. ${ }^{53}$ Furthermore, the inextensional wrapping of flat membranes assumes membranes of zero thickness making this a unique deployable structure, difficult to classify clearly.

In the section regarding cable and membrane structures, most of the examples presented are demountable structures, not deployable. Such structures are designed as kitof-parts ${ }^{54}$ systems made of basic components that can be reconfigured, substituted and reused. They are transported in a number of sections to then be assembled on site. The only cable and membrane structure that incorporates a kinematic mechanism is the retractable umbrella by Otto and Rasch. ${ }^{55}$ Nonetheless, the tensile aspect of the structure is limited to achieving pre-stress once deployed and does not contribute to the deployment mechanism, and for this reason, Merchan ${ }^{20}$ awards these structures their own category.

Air-inflated and air-supported structures are the sub-categories relative to pneumatic structures. The world's first supported radar cover was constructed by Walter Bird in 1948, and he presented his overview at the 1st International Colloquium on Pneumatic Structures in 1967.56 Graham Stevens ${ }^{57}$ was one of the conference attendees and was particularly inspired to start creating his own pneumatic artwork. Most of the air-inflated structures presented by Gantes can be classified as air beams: air-inflated tubes that act as beams or arches in supporting a fabric structure. However, the air-inflated category may also include air cells where double-surface pillows acquire stiffness by means of air pressure. ${ }^{58}$ The one structure mentioned by Gantes that was designed following a similar principle is the touring, exhibition and conference hall by Apicella and Thomas, although the project was never realised. ${ }^{59}$ The design for an air cell structure that was proposed before Gantes wrote his book is the Croydon Culture-Drome, ${ }^{60}$ a proposal for a pneumatic envelope to allow utilising the rooftops of multistorey car parks; however, it is not mentioned in the book (Figure 5).

Tensegrities $^{61}$ are introduced by stating the principle of segregating tension from compression. Gantes proposes classic tensegrities such as Snelson's Needle Tower ${ }^{62}$ and more unconventional structures where the tension is not resisted by cables but rather tensile fabric. ${ }^{63}$ From a morphological point of view, it is worth considering whether the fact that a surface undergoes tension, rather than cables, makes this kind of tensegrity a hybrid rather than a strut structure.

As previously stated, Gantes' class of retractable roofs diverges from the morphological approach and steers towards choosing application as a classification parameter which is useful for practicing engineers to identify precedents but does not necessarily highlight analysis and design strategies based on structural and kinematic performance. He subdivides this category in linearly moving systems ${ }^{64}$ radially rotating systems ${ }^{65}$ and hybrids. ${ }^{66}$ However, the examples proposed follow mechanism that apply also to other deployable structures making this last category superfluous.

Gantes' approach to extra-terrestrial structures is slightly different as no classification grouping is made. Instead, he presents several deployable space structures, ranging from theoretical conceptual models through to inservice solutions. However, the structures could be allocated a classification proving that the distinction between their applications is not necessarily relevant when considering their morphology and kinematics.

\section{Pellegrino}

Prof. Sergio Pellegrino has been among the leading researchers in deployable structures for a number of years, 


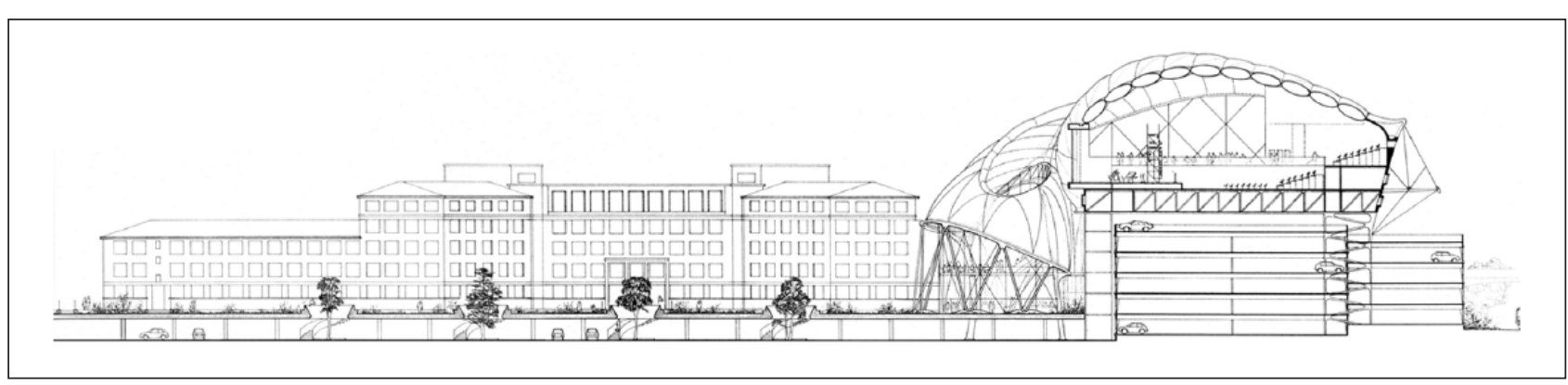

Figure 5. Section of Croydon Culture-Drome. ${ }^{60}$

proposing several new concepts such as cable-stabilised pantographs for deployable reflector antennas, ${ }^{67,68}$ retractable domes ${ }^{69,70}$ and lightweight radar structures. ${ }^{71}$ Pellegrino founded the Deployable Structures Laboratory at the University of Cambridge in 1990 and is now Joyce and Kent Kresa Professor of Aeronautics and Professor of Civil Engineering as well as Jet Propulsion Laboratory Senior Research Scientist. ${ }^{72}$

In the first chapter of Deployable Structures, ${ }^{73}$ a collection of lecture notes of the course Deployable Structures, held at CISM on 5-9 July 1999, unlike Gantes, Pellegrino does not consider application as such a determining factor in the defining of deployable structures. In fact, the kinetic motions and mechanisms remain the same, independently of what a deployable structure is used for. Although application is not regarded as a crucial classifying parameter, most of the authors' research is aimed at space structures, ${ }^{24,74,75}$ this is why the majority of the examples are relative to extra-terrestrial applications (see Figure 6).

While Pellegrino provides a comprehensive list of structures able to withstand large geometrical deformations grouped together, explicit classification criteria is not offered. Pellegrino's work is valuable as it approaches the subject of structural form from a motion perspective, then, providing an ensemble of examples to give the readers an idea of the potential of deployable structures. He refers to specific deployable structures, which previous authors do not necessarily mention, such as coilable masts, ${ }^{76}$ bi-stable structures such as the Taco Shell reflector ${ }^{77}$ and the mirror membrane deployed by centrifugal forces in the spatial experiment Znamya-2. ${ }^{78}$ Nonetheless, the field of deployable structures is considerably broader than that portrayed by Pellegrino who does not mention fundamental deployable structures such as tensegrities ${ }^{79,80}$ that were used in space applications as well as earth-based and deployable reciprocal frames. ${ }^{81,82}$ This is not to say that Pellegrino never acknowledges tensegrities in his research, as indeed he worked on developing deployable space structures based on such principles, ${ }^{83,84}$ rather that they are not explicitly mentioned or classified in the chapter 'Deployable structures in engineering'. 73

Pellegrino and colleagues'85,86 work on deployable structures contributed to his significant influence on the related field of deployable appendages for space applications where he does produce reviews of the state of the art of space arms and appendages.

\section{Hanaor and Levy}

During the same year, a cooperation between Hanaor and Levy ${ }^{38}$ produced a detailed classification for deployable structures. The research was mainly focused on architectural spaces but, at the same time, considered applications in space, without making application a parameter for classification. The authors generated a two-way distinction: morphological and kinematic. Morphological sub-categories are skeletal or lattice structures and continuous or stressed-skin structures, while kinematic sub-categories are rigid link systems and deformable components. A further parameter is added relatively to the previous classifications based on the way in which deployment occurs: the kinematic properties. In the text, the authors mention a third morphological class which combines skeletal and stressed-skin components that have an approximately equal role in the load-bearing hierarchy; however, these are not presented in their table (Figure 7).

The classification is comprehensive, covering many deployable forms and mechanisms, paying attention to details and definitions and making sure not to fall into the mistake of generalising or bypassing small but significant differences. The classification table has been referenced and used by many other authors. ${ }^{7,54,87}$

Not denying the classification's success, some deficiencies must be pointed out. For example, due to Hanaor and Levy having created the classification 15 years ago, there are some classes of structures missing that have appeared since. Also, other deployable structures, which already existed, such as STEM $^{88}$ or coilable ${ }^{89}$ structures were not considered within the table, probably as more relative to space applications. The authors mention hybrid structures as being a combination of skeletal and stressed-skin components that carry the load in approximately equal percentage. However, such definition is rather confusing, as most fabric structures necessarily need some form of support provided by elements being in compression,,${ }^{90}$ meaning that according to Hanaor and Levy, any fabric structure is 


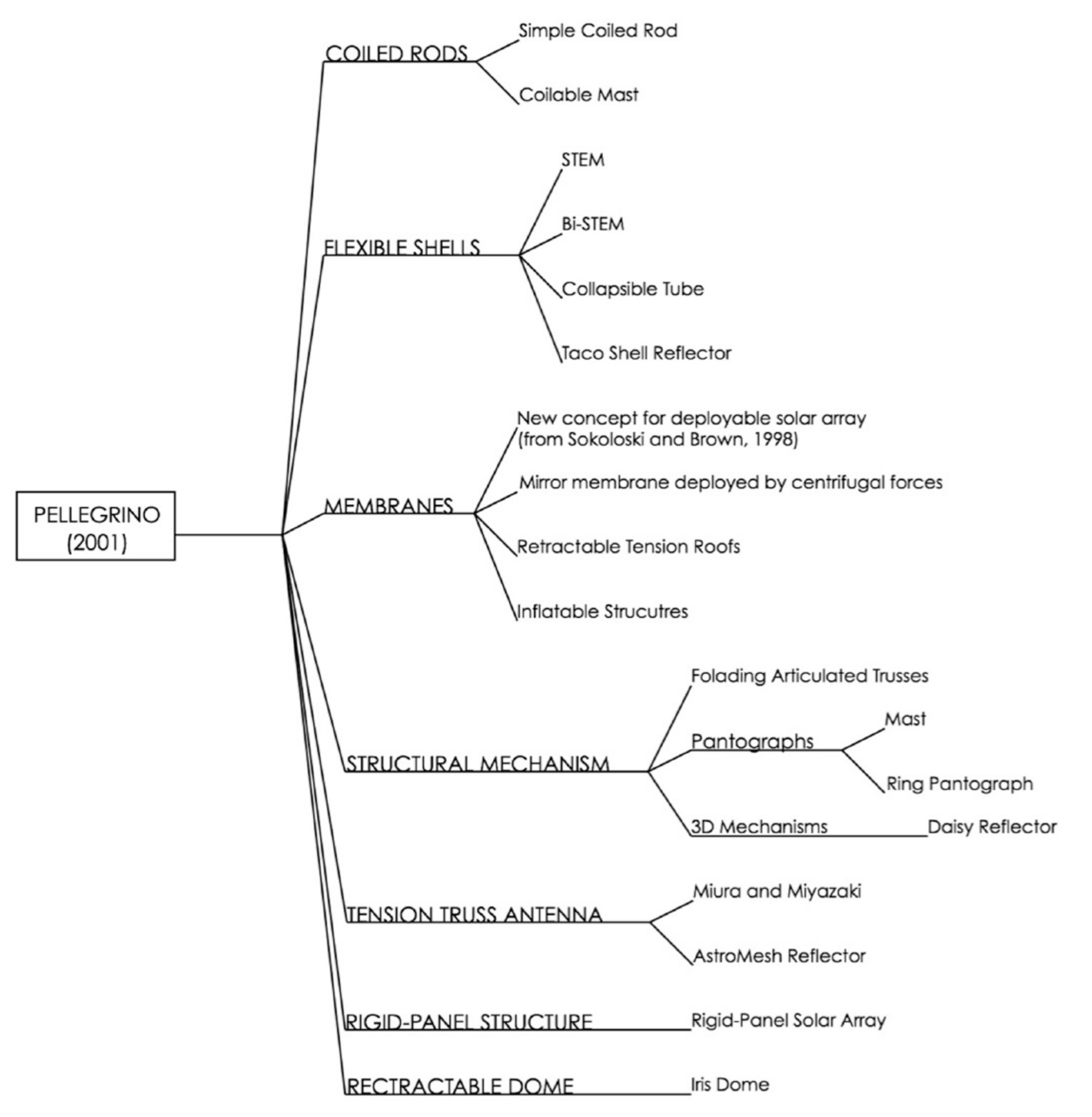

Figure 6. Classification by Pellegrino. ${ }^{73}$

a hybrid structure. A more appropriate definition of hybrid structures could be structures made of a combination of rigid links, deformable or flexible components. This interpretation is related to the structure's kinematics rather than its morphology and seems more compatible and sits logically in deployable structures classification. A tree diagram for the classification is presented in Figure 8.

\section{Korkmaz}

Prof. Korkmaz, ${ }^{91}$ working for the Department of Architecture at the İzmir Institute of Technology, Turkey, proposed an alternative classification for deployable structures. This classification was primarily concerned with the application of deployable structures in the sphere of architecture due to the author's background and interest. Korkmaz follows the definition by Fox and Yeh ${ }^{92}$ of kinetic architecture as comprising buildings, or components, with variable location and mobility in space and/or variable configuration and geometry. Taking the above definition as a starting point, kinetic structures are considered with regard to when the motion takes place, making the concept of 'time' a key parameter for the classification. When movement takes place before use and is the act creating the 


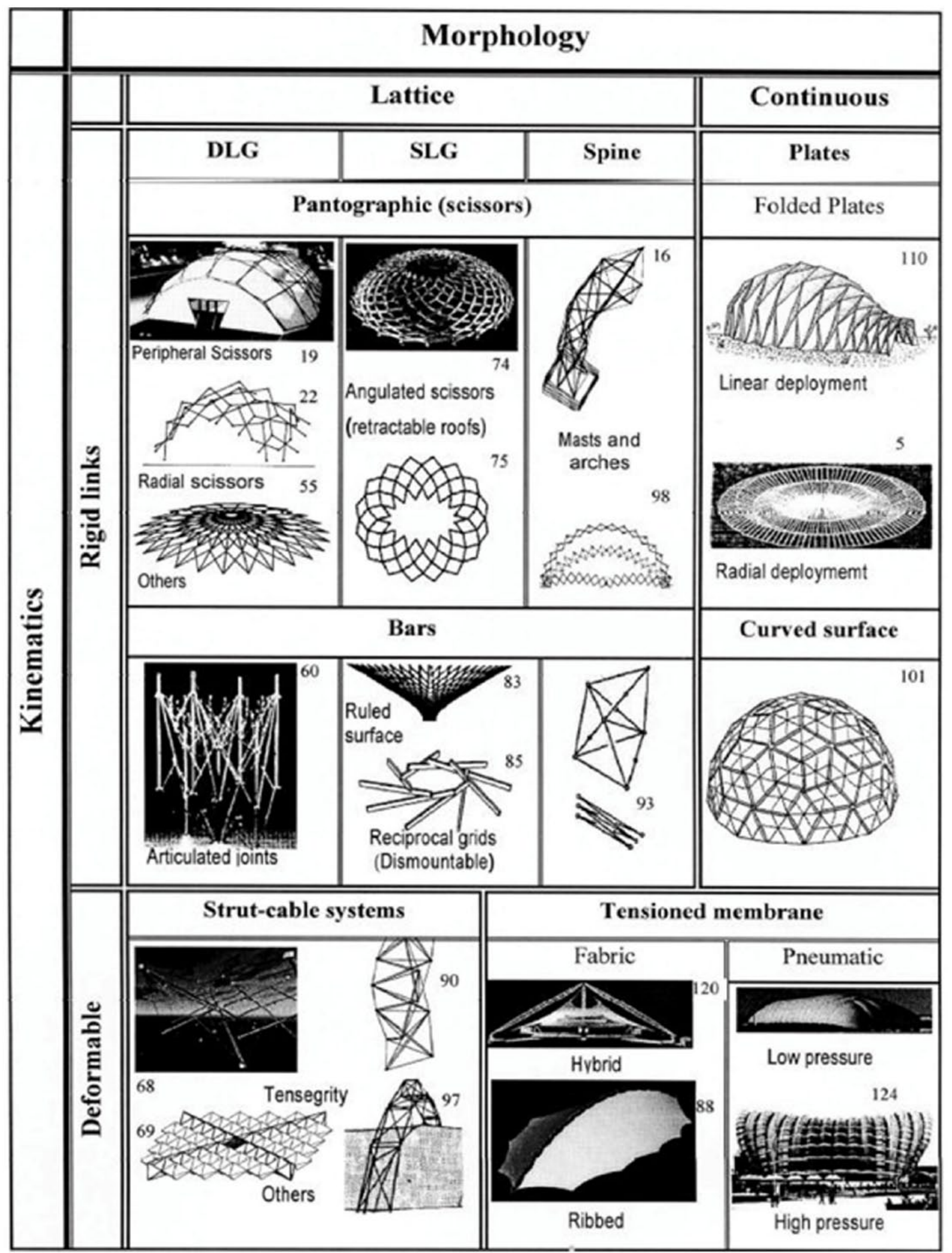

Figure 7. Classification table by Hanaor and Levy. ${ }^{38}$

structures' initial geometry, the type is referred to as buildings with variable location and mobility. Korkmaz further divides this group by using a classification by Kronenburg 93 based on deployment situations/locations, as shown in 


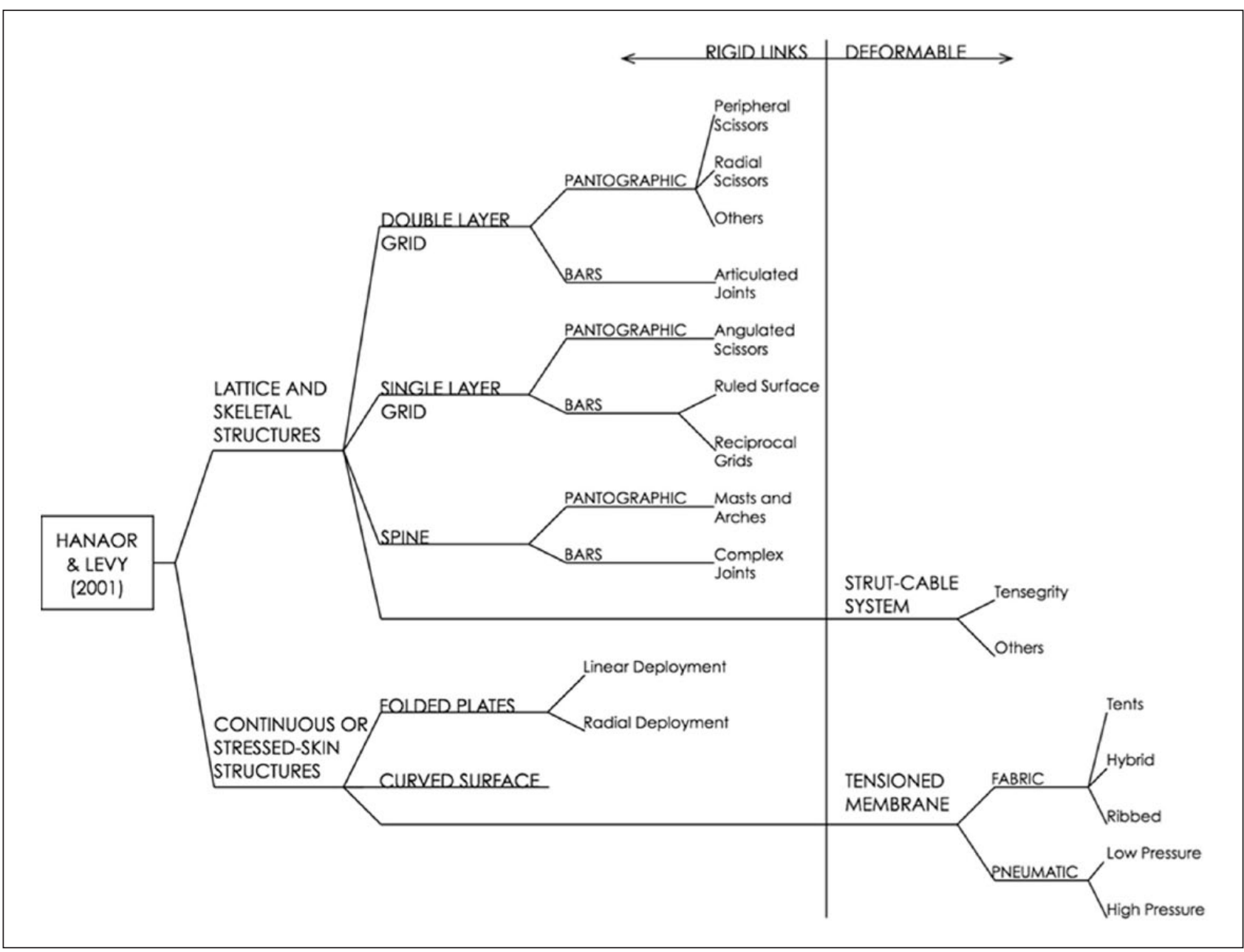

Figure 8. Classification by Hanaor and Levy. ${ }^{38}$

Figure 9. In the other building type, called buildings with variable geometry or movement, motion occurs after the geometry has been defined and the building used; the structure can adapt to future changes and modify its layout. The author dedicates greater attention to this last type of kinetic buildings on which he focuses his research. The next parameter of distinction is 'kinetic movement' that he tightly relates to 'material'. On one hand, soft forms ${ }^{94}$ can carry out a vast array of movements without the need for hinges or specific linkages, being movement inherent in the material. On the other hand, rigid forms can perform sliding, folding or rotating motions by means of joints connecting the structure's members. Rigid forms are, then, divided into surface structures and bar structures, the latter category then split between rigid structures with flexible or rigid cover material.

The distinction by Korkmaz between soft and rigid form buildings recalls the similar one by Hanaor and Levy between rigid link and deformable components. In fact, the authors refer to the same concept, only with a different terminology. However, both categorisations face a problem when trying to classify strut-cable systems. A pure tensegrity, ${ }^{32}$ where no compression elements are ever linked to one another, may fall under the deformable or soft form class, but strut-cable systems may also assume other arrangements ${ }^{95}$ (strut-strut connection), no longer fully complying with the class mentioned.

Moreover, Korkmaz neglects to carry out a more accurate classification of soft form buildings, unlike Gantes and Hanaor and Levy, who stress the differences existing within this class, for example, how pneumatic structures are different from tension membranes or tensegrities.

\section{From 2010 to now}

The decade following the year 2000 is prolific with researchers dedicating effort to offering a classification of deployable structures, which evolve mainly around the parameters of kinematics and morphology. After 2010, the authors started proposing classifications that offer a different point of view to the one previously suggested, such as the following: 


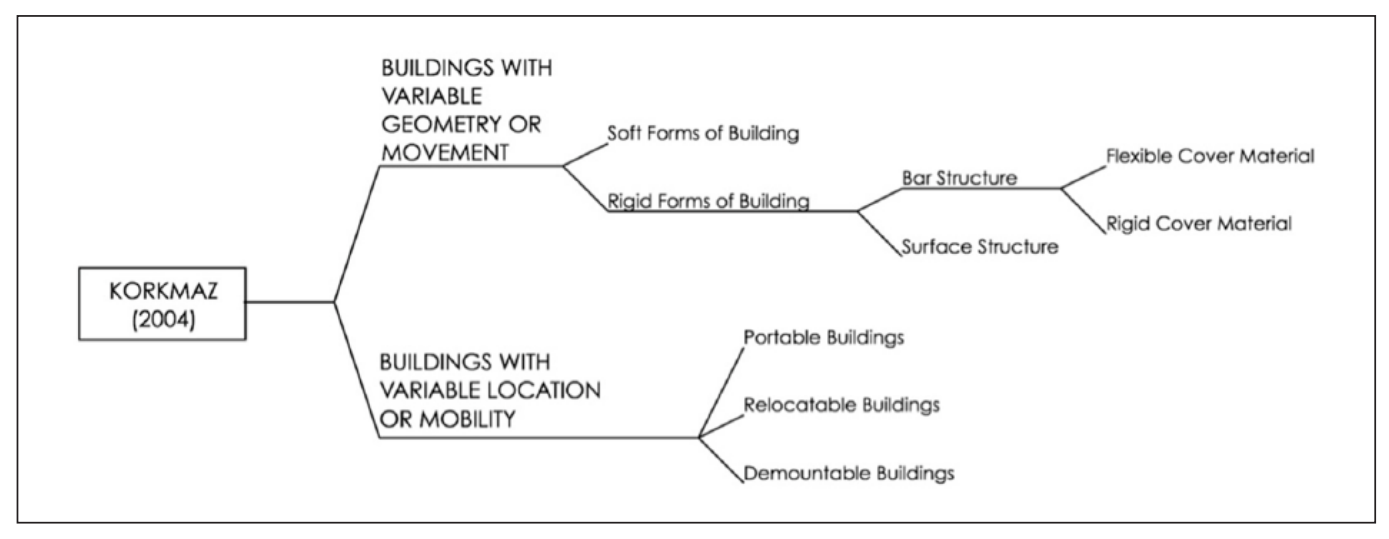

Figure 9. Classification by Korkmaz.91

- MOVE: Architecture in Motion - Dynamic Components and Elements by Schaeffer et al.:96

- Morphological Principles: Current Kinetic Architectural Structures by Stevenson; 97

- Deployable structures by Del Grosso and Basso; ${ }^{98}$

- Deployable Structures by Rivas Adrover. ${ }^{52}$

\section{Schaeffer and Vogt}

A classification of deployable structures transformations was adopted by Schaeffer et al., ${ }^{96}$ who differentiate between movement of rigid materials and deformable ones. For rigid materials, they state that there fundamentally are three basic types of movement: rotation, translation and a combination of the two, which is a common distinction used in robotics ${ }^{99}$ to describe motion. Deformable materials have a larger variety of movements.

Within deformable materials, soft and flexible materials are able to change shape permanently with the application of an external force, and elastic material resumes its original form after the deformation has occurred.

The authors also point out how, often, the way in which a structural assembly moves at a macro-scale may differ from the topology of movements that occur at a detailed level. For instance, let us consider tensegrities. The overall deployment of a tensegrity is dependent on the prestress of the tensile elements that will determine whether it is undeployed or fully deployed (see Figure 10). Thus, on a macro-scale, the structure transforms from a flat configuration to an open three-dimensional one. However, on a micro-scale, the topology of movement is different. In fact, depending on which elements are subject to the change in length, deployment can occur via strut mode, cable mode or mixed mode. ${ }^{62}$ In order for motion to occur, either the cables need to be tensioned through a system of pulleys or the struts need to be made out of telescopic bars.

\section{Stevenson}

A year later, Dr Stevenson, ${ }^{97}$ an architect and lecturer at the University of Liverpool, employed a different approach in the classification of deployable structures. Once again, because of her background and research, the application is mainly architectural. Morphology is what drives her decisions, by taking a synergetic view where the operations of the single parts are considered less relevant compared to the overall action of the architectural components. The nature and patterns of the single elements are considered at first, to then reinterpret them in connection with the overall motion and form. An important consideration stressed by the author is that of modularity. ${ }^{101}$ Components of deployable structures are often identical and organised by means of patterns. The creation of assemblies of functional units able to transmit movement from one element to the next is essential.

Due to the fact that Stevenson writes about half a decade after the other authors and considering the speed with which technology advances, the distinction between rigid and flexible materials is refined by the addition of a third kind: smart materials. Smart materials, also known as intelligent materials, transfer movement via changes in their physical properties and characteristics. However, material is not a defining parameter of the author's classification who, instead, recognises a spectrum of transformations, occurring in kinetic architecture, categorised as deform, fold, deploy, retract, slide and revolve. Deployable structures do not necessarily comply with only one of these types of transformations but may result in a combination of one or more types. The classification is represented in a two-way table as shown in Figure 11. The parameters along the sides are physical transformation against position in space and direction of transformation, similar to Hanaor and Levy's organisation of classification with morphology against kinematics.

One of the shortcomings noticed in Stevenson's classification is the difficulty in placing pneumatic structures within the table. Inflatable structures appear as an inverted 


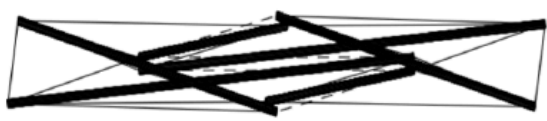

Undeployed configuration $(\tau=0)$

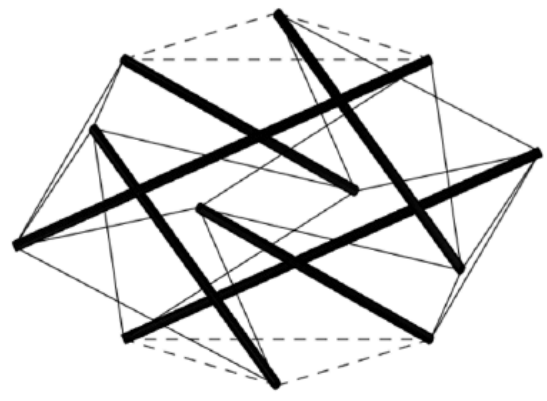

Intermediate configuration $(\tau=2 / 3)$

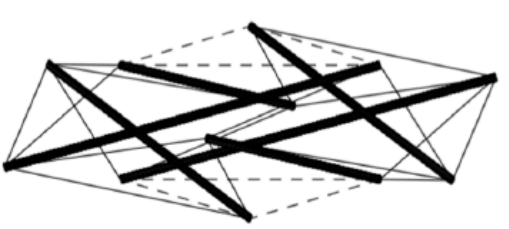

Intermediate configuration $(\tau=1 / 3)$

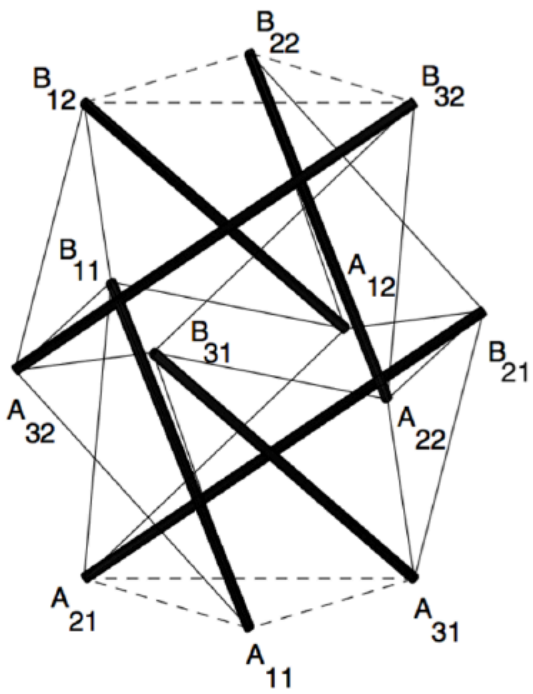

Deployed configuration $(\tau=1)$

Figure 10. Tensegrity deployment sequence by Sultan and Skelton. ${ }^{100}$

umbrella type, yet no differentiation between air-supported or air-inflated structures is mentioned. Pneumatic structures play a significant role in the world of deployable structures and should have a clear place in their classification. Pre-stressed cables and nets are not present in the classification table, although some designs are deployable.

\section{Del Grosso and Basso}

In 2013, Hanaor and Levy's classification table was referenced by Del Grosso and Basso ${ }^{102}$ who published a paper regarding deployable structures. Their first distinction underlines that by previous authors between deformable and rigid link deployables, see Figure 12.

The differentiator of this article comes from the mentioning of classes not considered by other authors before. These are compliant mechanism for deformable structures and morphing truss structures for rigid link structures. Just as standard mechanisms, compliant mechanisms transfer or transform motion, force or energy; however, they gain at least part of their mobility from the deflection of flexible members, rather than from movable joints exclusively. ${ }^{103}$ Such a category is relevant when looking at how the motion is carried out, but does not constitute a category for classifying deployable structures itself. For example, when we consider tensegrities, we know that they may deploy via strut mode and that such mode may imply telescopic elements. Nonetheless, this does not make tensegrities telescopic structures.

On the other hand, morphing truss structures ${ }^{104}$ consist of traditional truss structures where some of the elements are replaced with linear displacement actuators. Once again, the authors focus on the micro aspects of deployment, rather than looking at the overall morphological change occurring in the structure. Thus, although their consideration of there being elements with linearly varying length within the truss is valid, the truss will deploy as a hinged-collapsible-strut mechanism, a category proposed by Merchan. ${ }^{20}$

\section{Rivas Adrover}

The most recent classification is by the architect Esther Rivas Adrover (Figure 13). ${ }^{52}$ The book Deployable Structures is not peer reviewed, however, is a strong attempt at classifying deployable structures. Rivas Adrover's first distinction is based on the way deployable structures are developed: those created based on the structural components of 


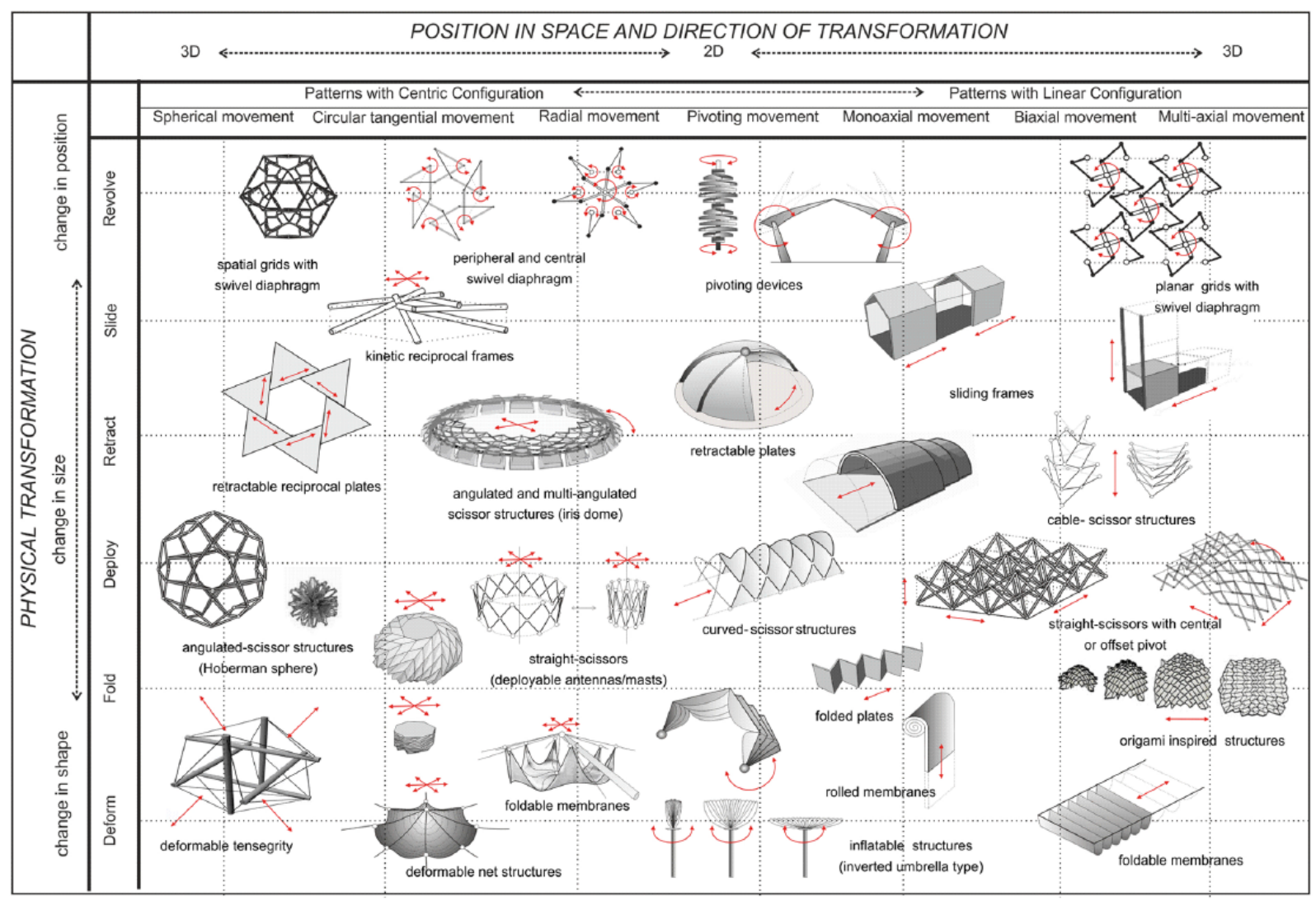

Figure II. Classification by Stevenson. ${ }^{97}$

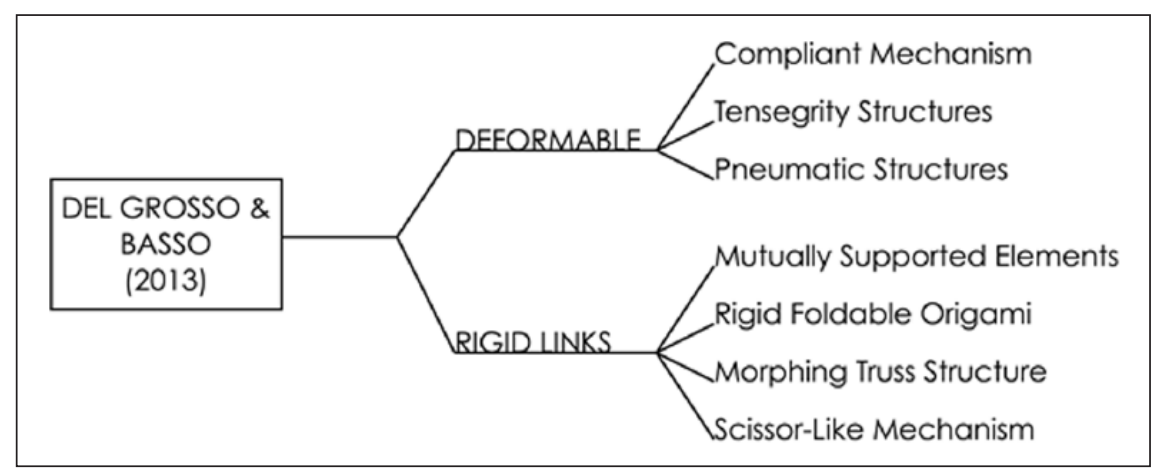

Figure 12. Classification by Del Grosso and Basso. ${ }^{102}$

the deployable mechanism (Structural Components) and those that are inspired by other sources (Generative Technique). For the purpose of this review, only Structural Components were considered as the Generative Technique section talks about where researchers draw inspiration for the creation of deployable structures, rather than focusing on their kinematics and morphology. The author explains how traditionally two types are generally recognised: rigid deployable components and deformable deployable components. However, some structural topologies do not belong to either, making way for the introduction to two other classes: flexible deployables and combined deployables. The subcategories following from these four classes present specific examples and some theory behind the functioning of the mechanisms.

Rivas Adrover's classification has some conflicts with previous work with regard to morphology considerations; for example, strut-cable systems such as tensegrities ${ }^{105}$ are classified under combined deployables, while these topologies are better represented under deformable deployable components. In fact, pure tensegrities have no rigid connections, although presenting stiff members (assuming 


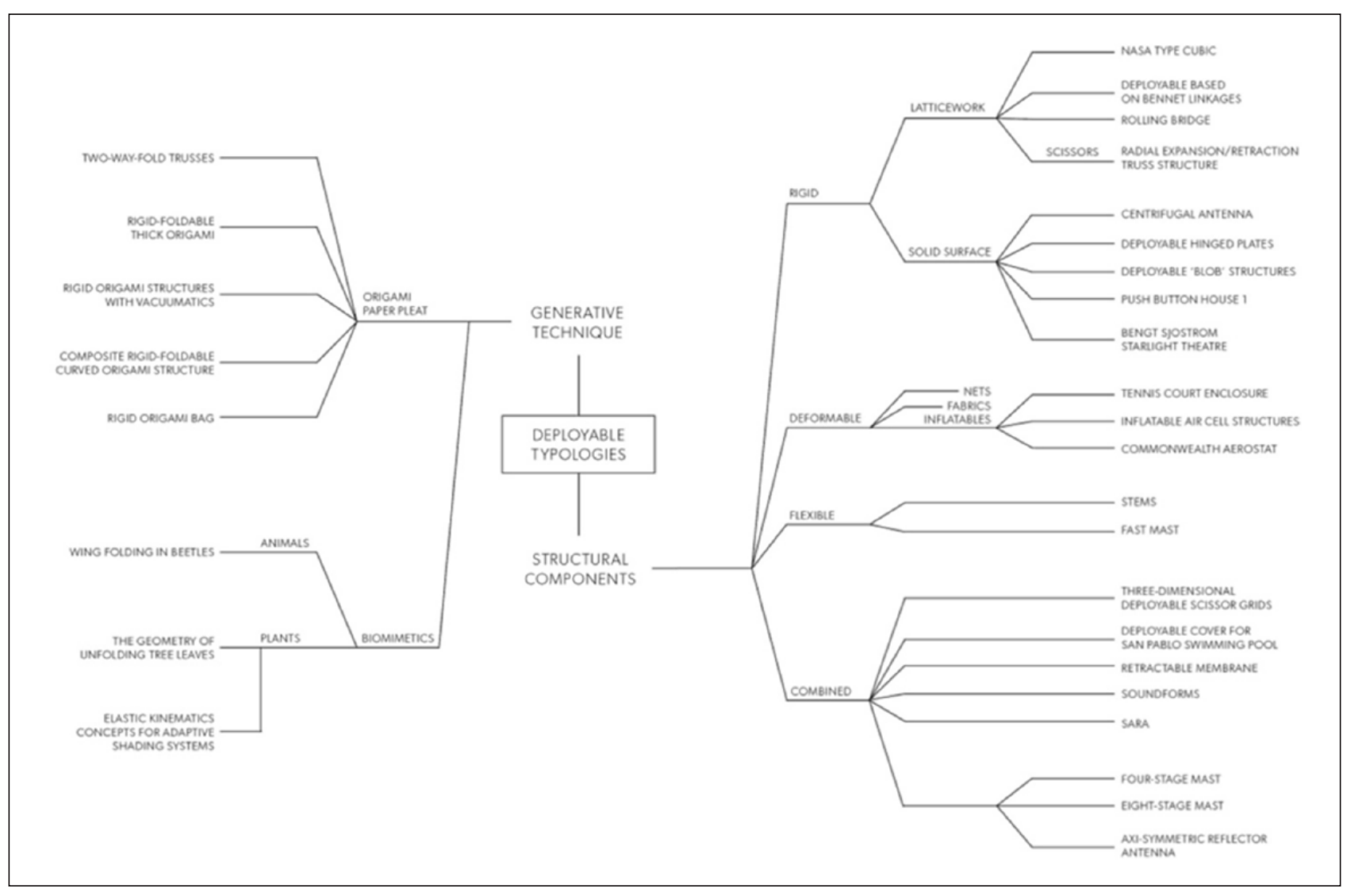

Figure 13. Classification by Rivas Adrover. ${ }^{52}$

adequate pretension ${ }^{106}$ ), and have many potential ways of deploying, although are not as easily controlled as rigid deployable components.

This inaccuracy is a consequence of Rivas Adrover's definition of deformable deployables. Rivas Adrover includes nets, fabrics and inflatables saying how these structures undergo large deformations. She then mentions that their deployment can only be controlled when they are combined with other structural components, referring the reader to the chapter of combined deployables. However, deformable deployable structures without any compression boundary or structural components only include inflatable structures, as nets and fabrics cannot achieve stability and equilibrium without some form of compression elements or anchored position at a boundary.

Moreover, specific examples are presented without assigning them to a more general subclass that is able to include other structures based on the same principle. For example, consider the first structure presented under rigid component deployables - latticework: NASA Type Cube. ${ }^{107}$ Such structures, based on symmetry transformations, should be classified as non-self-crossing linkages so that also other structures may be included, such as certain types of folding articulated trusses ${ }^{108}$ and Heatherwick and Rowe's ${ }^{109}$ rolling bridge (Figure 14).
Although Rivas Adrover mentions these structures, she does not group them in their own distinct class but leaves them under the more general class of latticework, along with pantographs. Yet, latticework deployable structures also comprise ruled surfaces and reciprocal fames that are neither mentioned nor presented with an example. It can be said that Rivas Adrover provides specific examples in certain circumstances but then misses out on concentrating the attention on their common morphological characteristics and neglects some other structures belonging to that morphological and/or kinetic group.

Relatively to flexible deployables, only STEMs and folding articulated trusses are presented, although many other flexible deployable structures exist (coilable truss, ${ }^{110}$ STACER ${ }^{111}$ ). Finally, the combined deployables section includes some folding roof structures, which incorporate fabric structures. However, the bearing capacity and deployment mechanism is carried out mainly by the grids, with the fabric only conferring some stability in the locked, fully deployed state or providing secondary covering surfaces. ${ }^{112}$ These structures are better included into the rigid deployable components - grids section.

The retractable roof by Kawaguchi ${ }^{113}$ is an unusual form of deployable structure utilising a membrane structure connected with two boundary compression rings that 


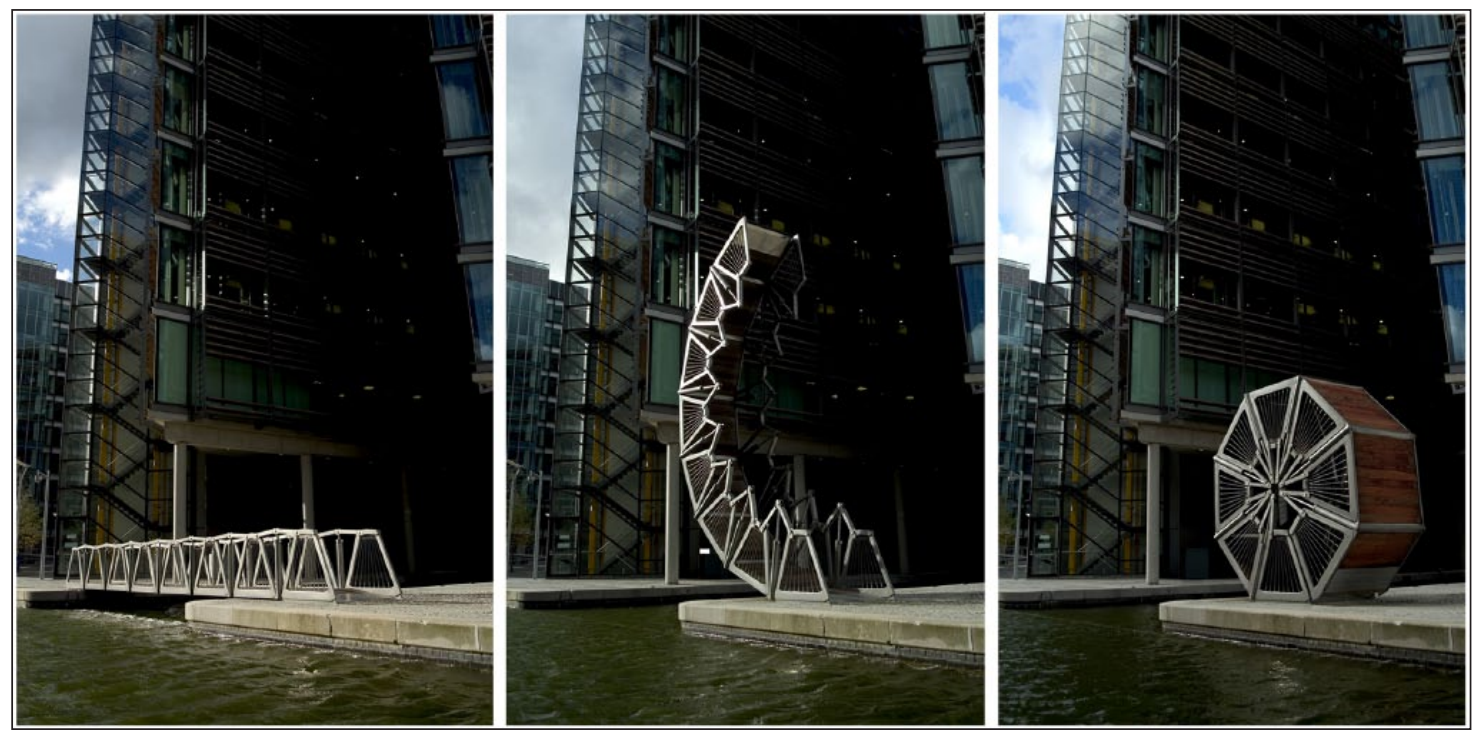

Figure 14. Rolling Bridge by Heatherwick Studio (photo by Steve Speller). ${ }^{109}$

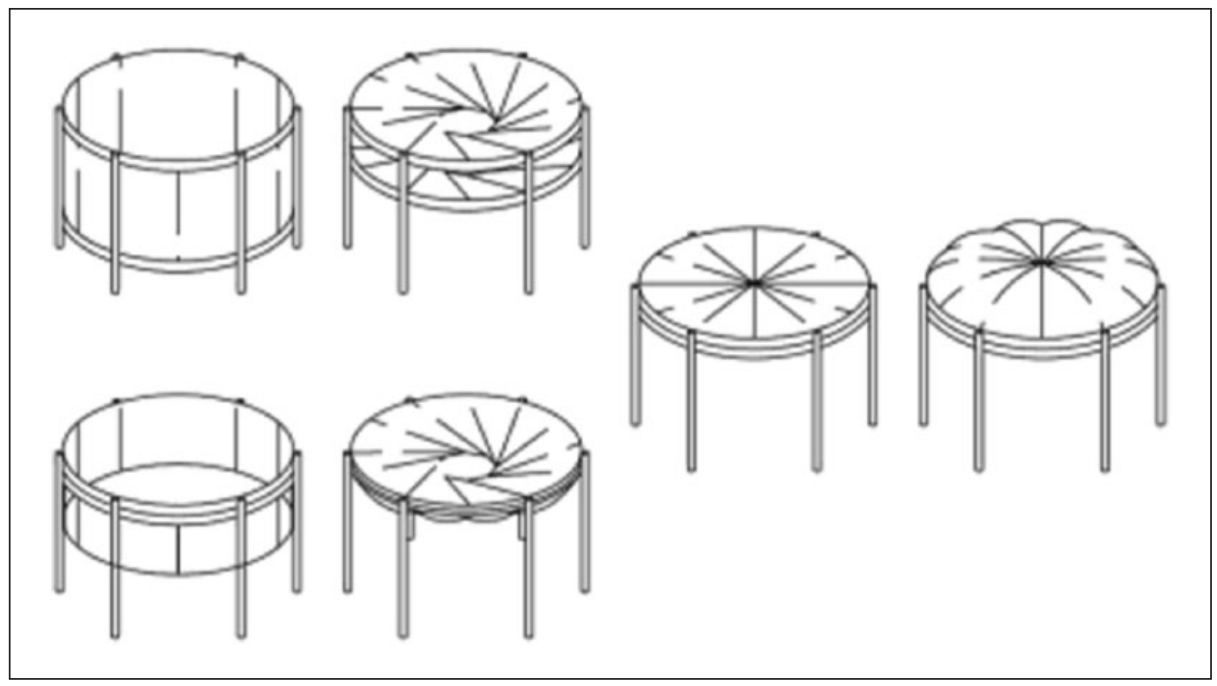

Figure 15. Retractable air-inflated membrane roof. I/3

rotate relatively to one another causing the membrane to fold/unfold (Figure 15). Additional stiffness can be obtained through introducing pre-stress to the membrane via air pressure or by creating a membrane of a slightly smaller size, thus causing it to stretch into its taut shape and is reliant on appropriately compensated cutting patterns. The air inflation is a means to achieve tension in the membrane and thus rigidity; nonetheless, the deployment of the structure occurs via folding tensile material. The structure is best classified as a boundary tension membrane, not as a hybrid structure.

The outdoor portable stage, Soundforms, is a portable structure, rather than deployable, as Rivas Adrover points out. Its external skin is made of polyvinyl chloride (PVC)coated polyester cushions based on the principle of airinflated structures; however, the rest of the structure does not present deployable features apart from the trusses being assembled on the ground and then being pivoted into position. ${ }^{114}$ Such structure is a portable/demountable structure, rather than a combined deployable one. In fact, the acoustic shell is not able to change its configuration but is lightweight and, once disassembled, packs into the smallest possible space for transport.

SARA (switch activated response algorithm) by Silver et al. ${ }^{115}$ falls into the category defined by Stevenson as smart materials; in fact, a small electronic pulse raises the temperature of the nickel-titanium wire causing a change in length. This readily deployable structure is rightly classified as hybrid as combining a pin-jointed frame made of 13 cells, 12 spacers, 100 muscle wires and 13 eight-bit serial chips based on a binary map. These particular kinds of structures are the result of multidisciplinary ${ }^{116}$ studies 
where electronics, programming and structural engineering are combined to output efficient solutions.

For tensegrities, Rivas Adrover only presents examples of applications in space. Two of them have bi-stable elements, ${ }^{117}$ while the axi-symmetric reflector antenna is a concept based on quasi-geodesic nets and hexagonal tensegrity modules ${ }^{75}$ which deploy by means of telescopic masts. These are particular ways to employ the tensegrity principles combined with others and fit the definition of hybrid structures perfectly; however, as previously stated, pure tensegrities (strut to cable connection only) are more appropriately classified under deformable component deployables.

\section{Other authors}

The authors discussed above either have attempted to classify deployable structures across several family types or have contributed significant works spanning several forms of deployable structures. These reviews have been analysed in a chronological order; nonetheless, there are a few other authors worth mentioning. A short review of deployable structures was published by Doroftei and Doroftei ${ }^{87}$ who considered four main groups: spatial bar structures (hinged bars), foldable plate structures (hinged plates), strut-cable systems (tensegrities) and membrane systems. The authors concentrate mainly on the first two classes of deployable structures, by looking at the different kinds of pantographic systems and case studies of plate structures.

The same classification is also acknowledged by De Temmerman ${ }^{22}$ in his doctoral thesis, who then refers back to Hanaor and Levy's classification table. Friedman ${ }^{118}$ also presents a review of deployable structures in her doctoral thesis; however, she herself specifies that this is not exhaustive, and her focus is limited to architectural and civil engineering applications. She proposes a similar review a couple of years later for a paper on structures undergoing large displacements. ${ }^{119}$

Other more specific classifications exist, which focus on one of the subclasses mentioned above; for example, Escrig and Valcarcel ${ }^{49}$ provide a hierarchy for scissorhinged mechanisms (pantographs), also investigated by Langbecker ${ }^{120}$ who proposed a systematic method for analysing such structures from a kinematic perspective. Prof. Escrig $^{48,121}$ from the School of Architecture at the University of Seville conducted prolific research in cooperation with J. Sanchez and J.P. Valcarcel on spherical grids composed of two-way scissors and how to generate them from grids that divide the surface of a sphere.

A different approach was adopted by Ramzy and Fayed $^{122}$ who present a classification of deployable structures based on their environmental performance distinguishing kinetic systems into skin-units systems, retractable elements, revolving buildings and biomechanical systems. After a short review of other classification methods by the Kinetic Design Group in the MIT institute, the analysis suggested is based on factors such as system configuration, control technique and cost and, in general, is more prone to consider environmental performance and human comfort than the mechanisms and physical transformation that such structures go through. A review of retractable membrane roofs was proposed by Mollaert ${ }^{123}$ who identifies those where the supporting structure is stationary (parallel, central and circular sliding) and those with a moving supporting structure (sliding, central folding and rotating). Prior to this, a historical survey of cable and membrane roofs was published by Forster. ${ }^{124}$

With regard to space applications, other specific reviews exist such as Santiago-Prowald and Baier ${ }^{125}$ who focus on space antennas and reiterate the different approaches of deployment of structures based on quasirigid members and highly flexible structures or a combination of the two (hybrid). With a kinematic perspective, the deployment is classified as either planar or three-dimensional, and many examples of space structures are discussed. However, deployable booms and masts have been reviewed by Puig et al. ${ }^{126}$ who list inflatable, telescopic, articulated, coilable, shape memory composite booms and deployable truss structures. Similar antecedents include other arm development reviews. ${ }^{85,127}$

Having reviewed all the above classifications, the lack of a complete, comprehensive and up-to-date classification of deployable structures is evident. The most exhaustive one so far is the classification by Hanaor and Levy, which has been referenced extensively in the literature following it. However, the classification was published in 2001, and new developments and technologies have arisen since then, so there is the need for an updated deployable structures classification with a common vocabulary that all those working in this field may refer to.

\section{Conclusion}

The popularity of deployable structures has increased since the latter half of the 20th century as they introduce a novel and unique type of engineering, which allows structures to be packaged into a small configuration, for example, for transportation, and to be expanded and opened when needed. Retaining the functionality of traditional structures, they are able to undergo large configuration variations in a controlled and autonomous manner. Applications are close to limitless and vary considerably in scale if one compares an expandable stent graft used to perform minimal invasive surgery on the human body to the retractable roofs of big stadium arenas.

Because of the plethora of mechanisms and ways in which deployment can occur, creating a reasonable classification of deployable structures is an arduous task. Several reviews and classifications have been proposed so far; however, some are now obsolete due to progress in the field, others misclassify and some are simply a list of deployable structures rather than an attempt to order according to specific criteria and thus of 
limited value in constructing a common vocabulary and understanding of this field.

The work here chronologically presented evaluates existing deployable structures reviews and classifications, by proposing tree graphs for each of them, in order to offer a consistent output for the readers to take in and compare. Trends have been recognised within the literature as well as incorrect definitions or classification decisions. Additionally, some of the texts analysed date back some years, thus lacking the integration of some deployable structures more recently developed.

In conclusion, there is, to date, a considerable volume of literature regarding deployable structures spanning at least three decades, and the research is ongoing meaning that the subject is continuously expanding and becoming more complex and harder to grasp as technologies and materials continue to grow. This research has highlighted the current gap in the literature for a current and consistent classification system for deployable structures and the need for a common vocabulary to act as a reference tool to aid the clear understanding of the variety, breadth and interrelations existing in the world of deployable structures. Such classification system will have to be continuously updated as new discoveries are made in the field.

\section{Declaration of conflicting interests}

The author(s) declared no potential conflicts of interest with respect to the research, authorship and/or publication of this article.

\section{Funding}

The author(s) received no financial support for the research, authorship and/or publication of this article.

\section{References}

1. Kiper G and Söylemez E. Deployable space structures. In: Proceedings of the international conference on recent advances in space technologies, Istanbul, 11-13 June 2009, pp. 131-138. New York: IEEE.

2. Kronenburg R. Architecture in motion: the history and development of portable building. Oxon: Routledge, 2014.

3. Kuribayashi K, Tsuchiya K, You Z, et al. Self-deployable origami stent grafts as a biomedical application of Ni-rich TiNi shape memory alloy foil. Mat Sci Eng A: Struct 2006; 419: 131-137.

4. Kronenburg R. Flexible: architecture that responds to change. London: Laurence King Publishing, 2007.

5. Friedman N, Farkas G and Ibrahimbegovic A. Deployable/ retractable structures towards sustainable development. Pollack Period 2011; 6: 85-97.

6. Luchsinger R, Pedretti A, Steingruber P, et al. The new structural concept Tensairity: basic principles. In: Zingoni A (ed.) Progress in structural engineering, mechanics and computation. London: Taylor \& Francis Group, 2004, pp. 323-328.
7. De Temmerman N, Alegria Mira L, Vergauwen A, et al. Transformable structures in architectural engineering. In: De Wilde WP, Brebbia CA and Hernández S (eds) High performance structures and materials VI. Southampton: WIT Press, 2014, pp. 457-468.

8. Stevenson A. Deploy. Oxford dictionary of English. 3rd ed. Oxford: Oxford University Press, 2010.

9. Pellegrino S. Deployable structures. Wien: Springer, 2001.

10. Hutchinson RG, Wicks N, Evans AG, et al. Kagome plate structures for actuation. Int J Solids Struct 2003; 40: 69696980.

11. Ramrakhyani DS, Lesieutre GA, Frecker MI, et al. Aircraft structural morphing using tendon-actuated compliant cellular trusses. J Aircraft 2005; 42: 1614-1620.

12. Gantes CJ. Section 10.3: deployable Structures. In: Munghan I and Abel JF (eds) Fifty years of progress for shell and spatial structures: in celebration of the 50th anniversary jubilee of the IASS (1959-2009). Madrid: International Association for Shell and Spatial Structures, 2011, pp. 373-390.

13. Akgün Y. A novel transformation model for deployable scissor-hinge structures, 2010, https://elib.uni-stuttgart.de/ bitstream/11682/368/1/ILEK_thesis_v_12_son.pdf

14. Tachi T. One-DOF cylindrical deployable structures with rigid quadrilateral panels. In: Proceedings of the international association for shell and spatial structures (50th 2009 Valencia) evolution and trends in design, analysis and construction of shell and spatial structures, Editorial Universitat Politècnica de València, València, 28 September-2 October 2009.

15. Gantes C, Connor JJ and Logcher RD. Combining numerical analysis and engineering judgment to design deployable structures. Comput Struct 1991; 40: 431-440.

16. Gantes CJ, Connor JJ, Logcher RD, et al. Structural analysis and design of deployable structures. Comput Struct 1989; 32: 661-669.

17. Zuk W and Clark RH. Kinetic architecture. New York: Van Nostrand Reinhold Company, 1970.

18. Rowan J. Progressive architecture. Philip H. Hubbard, 1968, New York, p. 93.

19. Susam G. A research on a reconfigurable hypar structure for architectural applications. İzmir: Graduate School of Engineering and Sciences, İzmir Institute of Technology, 2013.

20. Merchan CHH. Deployable structures. Cambridge, MA: Department of Architecture, Massachusetts Institute of Technology, 1987.

21. Schlaich J, Bergermann R and Sobek W. Tensile membrane structures. Bull IASSS 1990: 19-32.

22. De Temmerman N. Design and analysis of deployable bar structures for mobile architectural applications. Brussels: Vrije Universiteit Brussel, 2007.

23. Kaveh A and Davaran A. Analysis of pantograph foldable structures. Comput Struct 1996; 59: 131-140.

24. Pellegrino S and Kwan A. A new concept for large deployable space frames. Int J Space Struct 1994; 9: 153-162.

25. Miura K, Furuya H and Suzuki K. Variable geometry truss and its application to deployable truss and space crane arm. Acta Astronaut 1985; 12: 599-607. 
26. You Z and Chen Y. Motion structures: deployable structural assemblies of mechanisms. Abingdon: Spon Press, 2012.

27. Bechthold M. Innovative surface structures: technologies and applications. London: Taylor \& Francis, 2008.

28. Topham S. Blow-up: inflatable art, architecture and design. Munich; London: Prestel, 2002.

29. Tachi T. Rigid-foldable thick origami. Origami 2011; 5: 253-264

30. Pellegrino S and Vincent JFV. How to fold a membrane. In:Pellegrino S (ed.) Deployable structures. Vienna: Springer, 2001, pp. 59-75.

31. Vredevoogd J. Telescoping and laterally-movable mobile home system. Patent 3,605,351, USA, 1971.

32. Fuller RB. Tensile-integrity structures. Patent 3,063,521, USA, 1962.

33. Snelson KD. Continuous tension, discontinuous compression structures. Patent 3,169,611, USA, 1965.

34. Bird WW. Dual wall air inflated structure. Patent 3,247,627, USA, 1966

35. Bird WW. Air inflated fabric structures. Patent 3,059,655, USA, 1962.

36. Jensen FV. Concepts for retractable roof structures. Cambridge: University of Cambridge, 2005.

37. Gantes CJ. Deployable structures: analysis and design. Southampton: WIT Press, 2001.

38. Hanaor A and Levy R. Evaluation of deployable structures for space enclosures. Int J Space Struct 2001; 16: 211-229.

39. Gantes C. A design methodology for deployable structures. Cambridge, MA: Massachusetts Institute of Technology, 1991.

40. Piñero EP. Project for a mobile theatre. Archit Design 1961; 12: 145-155.

41. Foster C and Krishnakumar S. A class of transportable demountable structures. Int J Space Struct 1986; 2: 129-137.

42. Berger H. Light structures - structures of light: the art and engineering of tensile architecture. Basel: Birkha\0308user, 1996.

43. Herzog T and Bacon S. Pneumatic structures: a handbook for the architect and engineer. St Albans: Crosby Lockwood Staples, 1977.

44. Ishii K. Structural design of retractable roof structures. Southampton: WIT Press, 2000.

45. Otto F and Burkhardt B. Convertible roofs. Institute for Leightweight Structures, University of Stuttgart, IL5. 1972.

46. Hale GA and Hale TA. Inflatable structure. Patent 5,570,544, USA, 1996.

47. Zeigler TR. Collapsible self-supporting structure. Patent 3,968,808, USA, 1976.

48. Escrig F, Sanchez J and Valcarcel JP. Two way deployable spherical grids. Int J Space Struct 1996; 11: 257-274.

49. Escrig F and Valcarcel JP. Geometry of expandable space structures. Int J Space Struct 1993; 8: 71-84.

50. Piekarski M. Constructional solutions for two-way-folddeployable space trusses. In: Pellegrino S and Guest SD (eds) IUTAM-IASS symposium on deployable structures: theory and applications: proceedings of the IUTAM symposium held in Cambridge, 6-9 September 1998. Dordrecht: Springer, 2000, pp. 301-310.

51. Guest SD and Pellegrino S. Inextensional wrapping of flat membranes. In: Motro R and Wester T (eds) Proceedings of the first international seminar on structural morphology, Montpellier, 1992, pp. 203-15.

52. Adrover ER. Deployable Structures. London: Laurence King Publishing, 2015.

53. Tonon OL. Geometry of spatial folded forms. Int J Space Struct 1991; 6: 227-240.

54. De Temmerman N, Roovers K, Alegria Mira L, et al. Lightweight transformable structures: materialising the synergy between architectural and structural engineering. In: De Temmerman $\mathrm{N}$ and Brebbia CA (eds) Mobile and rapidly assembled structures $I V$. Southampton: WIT Press, 2014, pp. 1-20.

55. Otto F and Rasch B. Finding form: towards an architecture of the minimal. Germany: Deutscher Werkbund Bayern, 1995.

56. International Colloquium on Pneumatic Structures. Proceedings of the 1st international colloquium on pneumatic structures. Stuttgart: University, IASS, 1967.

57. McLean W and Silver P. Air structures. London: Laurence King Publishing, 2015.

58. De Luca NP, Reyes OM and Jacques PM. Inflatable, cushioning, bubble wrap product having multiple, interconnected, bubble structures. Patent 6,410,119, USA, 2002.

59. Kronenburg R. Portable architecture. 3rd ed. Oxford: Elsevier/Architectural Press, 2003.

60. Birds Portchmouth Russum. Croydon Culture-Drome. 1994, http:/www.birdsportchmouthrussum.com/pagegallery-2 (accessed 12 August 2016).

61. Emmerich DG. Structures tendues et autotendantes: Monographies de Géométrie Constructive. Paris: Editions de la La Villette, 1988.

62. Motro R. Tensegrity: structural systems for the future. London: Hermes Penton Science, 2003.

63. Shelter Systems. Portable affordable reliable: tensegrity-geodesic tent structures. United States, 1976-2015, http://www. shelter-systems.com/tensegrity.html (accessed 19 July 2016).

64. Apezteguia JM and Arrastoa JA. Retractable roof for a multi-purpose centre in San Sebastian. In: Escrig F and Brebbia CA (eds) Mobile and rapidly assembled structures II: 2nd international conference on mobile and rapidly assembled structures (MARAS 96). Seville: Computational Mechanics Publications, 1996, p. 371.

65. Tanno Y, Sasaki Y, Nakai M, et al. Fukuoka Dome, Japan. Struct Eng Int 1994; 4: 151-153.

66. Sugizaki K. Structural design of the deployable roof system "Super Circ Dome". In: Proceedings of the LASS symposium: spatial structures at the turn of the millennium. Copenhagen, Denmark: Kunstakademiets Forlag Arkitektskolen, 1991, pp. 109-116.

67. You Z and Pellegrino S. Cable-stiffened pantographic deployable structures. I - triangular mast. AIAA $J$ 1996; 34: 813-820.

68. You Z and Pellegrino S. Cable-stiffened pantographic deployable structures part 2: mesh reflector. AIAA J 1997; 35: $1348-1355$. 
69. Buhl T, Jensen FV and Pellegrino S. Shape optimization of cover plates for retractable roof structures. Comput Struct 2004; 82: 1227-1236.

70. Kassabian P, You Z and Pellegrino S. Retractable roof structures. P I Civil Eng: Str B 1999; 134: 45-56.

71. Pellegrino S. New concepts for spacecraft antennas and radar structures based on ultra-thin composites. In: Proceedings of the 46th Israel annual conference on aerospace sciences, Tel Aviv University, Faculty of Aerospace Engineering, Tel Aviv, Israel, 1-2 March 2006.

72. Mungan I and Abel J. Fifty years of progress for shell and spatial structures. Reino Unido: Multi-Science Publishing Co Ltd Essex, 2011.

73. Pellegrino S. Deployable structures in engineering. In:Pellegrino S (ed.) Deployable structures. Vienna: Springer, 2001, pp. 1-35.

74. Guest SD and Pellegrino S. A new concept for solid surface deployable antennas. Acta Astronaut 1996; 38: 103113.

75. Tibert $\mathrm{G}$ and Pellegrino S. Furlable reflector concept for small satellites. In: Proceedings of the 19th AIAA applied aerodynamics conference, Anaheim, CA, 11-14 June 2001. Reston, VA: American Institute of Aeronautics and Astronautics.

76. Natori M, Okazaki K, Sakamaki M, et al. Model study of simplex masts. In: 15th International Symposium on Space Technology and Science. Tokyo, Japan: AGNE Publishing, Inc., 1986, pp. 489-496.

77. Robinson SA. Simplified spacecraft antenna reflector for stowage in confined envelopes. Patent 5,574,472, USA, 1996.

78. McNally D. Znamya-2.5: one to watch. Astron Geophys 1998; 39: 4.

79. Furuya H. Concept of deployable tensegrity structures in space application. Int J Space Struct 1992; 7: 143-151.

80. Sultan C. Modeling, design, and control of tensegrity structures with applications. Lafayette, IN: Purdue University, 1999.

81. Chilton JC, Choo BS and Coulliette P. Retractable roof using the reciprocal frame. IABSE report, International Association for Bridge and Structural Engineering, Zurich, September 1994.

82. Saidani M and Baverel O. Retractable multi-reciprocal grid structure. J Int Assoc Shell Spat Struct 1998; 39: 141-146.

83. Tibert G and Pellegrino S. Deployable tensegrity reflectors for small satellites. J Spacecraft Rockets 2002; 39: 701-709.

84. Tibert $\mathrm{G}$ and Pellegrino S. Deployable tensegrity masts. In: Proceedings of the 44th AIAA/ASME/ASCE/AHS/ASC structures, structural dynamics, and materials conference, Norfolk, VA, 7-10 April 2003. Reston, VA: American Institute of Aeronautics and Astronautics.

85. Jensen F and Pellegrino S. Arm development review of existing technologies. Cambridge: Department of Engineering, University of Cambridge, 2001, p. 47.

86. Pellegrino S. Large retractable appendages in spacecraft. $J$ Spacecraft Rockets 1995; 32: 1006-1014.

87. Doroftei I and Doroftei I-A. Deployable structures for architectural applications - a short review. Appl Mech Mater 2014; 658: 233-240.
88. Rimrott FPJ and Fritzsche G. Fundamentals of STEM mechanics. In: Pellegrino S and Guest SD (eds) IUTAMIASS symposium on deployable structures: theory and applications: proceedings of the IUTAM symposium held in Cambridge, 6-9 September 1998. Dordrecht: Springer, 2000, pp. 321-333.

89. Webb JE and Mauch HR. Deployable lattice column. U.S. Patent 3486279. Washington, DC: Nasa, 1969.

90. Wakefield DS. Engineering analysis of tension structures: theory and practice. Eng Struct 1999; 21: 680-690.

91. Korkmaz K. An analytical study of the design potentials in kinetic architecture. İzmir: İzmir Institute of Technology, 2004.

92. Fox MA and Yeh BP. Intelligent kinetic systems in architecture. In: Nixon P, Lacey G and Dobson S (eds) Managing interactions in smart environments. London: Springer, 2000, pp. 91-103.

93. Kronenburg R. Houses in motion: the genesis, history and development of the portable building. London: Academy Editions, 1995.

94. Otto F, Trostel R and Schleyer FK. Tensile structures; design, structure, and calculation of buildings of cables, nets, and membranes. Cambridge, MA: The MIT Press, 1973.

95. Zhang L-Y, Zhao H-P and Feng X-Q. Constructing largescale tensegrity structures with bar-bar connection using prismatic elementary cells. Arch Appl Mech 2015; 85: 383-394.

96. Schaeffer O, Vogt MM and Scheuermann A. MOVE: architecture in motion - dynamic components and elements. Basel: Birkhäuser, 2010.

97. Stevenson CM. Morphological principles: current kinetic architectural structures. London: Adaptive Architecture, The Building Centre, 2011, pp. 1-12.

98. Del Grosso AE and Basso P. Deployable structures. $A d v$ Sci Tech 2013; 83: 122-131.

99. Jazar RN. Theory of applied robotics: kinematics, dynamics, and control. New York: Springer Science \& Business Media, 2010.

100. Sultan C and Skelton R. Deployment of tensegrity structures. Int J Solids Struct 2003; 40: 4637-4657.

101. Kishimoto N and Natori M. Hierarchical modular structures and their geometrical configurations for future large space systems. J Int Assoc Shell Spat Struct 2006; 47: 303-309.

102. Del Grosso AE and Basso P. Deployable structures. Adv Sci Tech 2013; 83: 122-131.

103. Howell LL. Compliant mechanisms. New York; Chichester: John Wiley \& Sons, 2001.

104. Inoue F. Development of adaptive construction structure by variable geometry truss. Rijeka: INTECH Open Access Publisher, 2008.

105. Skelton RE, Adhikari R, Pinaud JP, et al. An introduction to the mechanics of tensegrity structures. In: Proceedings of the 2001 40th IEEE conference on decision and control, Orlando, FL, 4-7 December 2001, vol. 5, pp. 4254-4259. New York: IEEE.

106. Guest SD. The stiffness of tensegrity structures. IMA J Appl Math 2011; 76: 57-66.

107. Britt AL and Lalvani H. Symmetry as a basis for morphological analysis and generation of NASA-type cubic deployables. In: Pellegrino S and Guest SD (eds) IUTAM-IASS symposium 
on deployable structures: theory and applications: proceedings of the IUTAM symposium held in Cambridge, 6-9 September 1998. Dordrecht: Springer, 2000, pp. 45-54.

108. Adams LR. The X-beam as a deployable boom for the space station. In: Proceedings of the 22nd aerospace mechanisms symposium, NASA Langley Research Center, Hampton, VA, 4-6 May 1988, pp. 59-66. Washington, DC: NASA.

109. Heatherwick T and Rowe M. Thomas Heatherwick: making. London: Thames \& Hudson, 2012.

110. Bowden M and Benton M. Design of deployable-truss masts for space station. In: Proceedings of the aerospace design conference, Irvine, CA, 16-19 February 1993. Reston, VA: American Institute of Aeronautics and Astronautics.

111. Pankow D, Besuner R, Wilkes R, et al. Deployment mechanisms on the fast Satellite: magnetometer, radial wire, and axial booms. In: Pfaff RF (ed.) The FAST mission. Dordrecht: Springer, 2001, pp. 93-111.

112. Escrig F. Expandable space structures. Int J Space Struct 1985; 1: 79-91.

113. Kawaguchi K. New Approach to retractable membranes structures. In: Pellegrino S and Guest SD (eds) IUTAMIASS symposium on deployable structures-theory and applications. Dordrecht; Boston, MA: Kluwer Academic Publishers, 2000, pp. 193-199.

114. Stephenson M, Flanagan J, Bavister P, et al. Sound shell. Patent 8,430,199, USA, 2013.

115. Silver P, Dodd F, Holdon T, et al. Prototypical applications of cybernetic systems in architectural contexts: a tribute to Gordon Pask. Kybernetes 2001; 30: 902-920.

116. Wang Z-1 and Kang ZC. Functional and smart materials: structural evolution and structure analysis. New York: Springer Science \& Business Media, 2012.
117. Tibert G. Deployable tensegrity structures for space applications. Stockholm: Department of Mechanics, KTH Royal Institute of Technology, 2002.

118. Friedman N. Investigation of highly flexible, deployable structures: review, modelling, control, experiments and application. Ecole Doctorale Sciences Pratiques, École normale supérieure de Cachan - ENS Cachan, Budapest University of Technology and Economics, Budapest, 2001.

119. Friedman N and Ibrahimbegovic A. Overview of highly flexible, deployable lattice structures used in architecture and civil engineering undergoing large displacements. YBL J Built Environ 2013; 1: 85-103.

120. Langbecker T. Kinematic analysis of deployable scissor structures. Int J Space Struct 1999; 14: 1-15.

121. Escrig F, Valcárel JP and Sánchez J. Roofing geometry of deployable x-frames. Int J Space Struct 1998; 13: 1-12.

122. Ramzy N and Fayed H. Kinetic systems in architecture: new approach for environmental control systems and contextsensitive buildings. Sustain Cities Soc 2011; 1: 170-177.

123. Mollaert M. Retractable membrane roofs. WIT Trans Built Env 1996; 24: 407-417.

124. Forster B. Cable and membrane roofs - a historical survey. Struct Eng Rev 1994; 6: 145-174.

125. Santiago-Prowald J and Baier H. Advances in deployable structures and surfaces for large apertures in space. CEAS Space J 2013; 5: 89-115.

126. Puig L, Barton A and Rando N. A review on large deployable structures for astrophysics missions. Acta Astronaut 2010; 67: 12-26.

127. Rauschenbach HS. Solar cell array design handbook: the principles and technology of photovoltaic energy conversion. New York; London: Van Nostrand Reinhold, 1980. 